\title{
Trends of poisoning in Rajkot region- A retrospective study
}

\author{
Jitendra S Rathod ${ }^{1}$, Hetalkumar Kyada ${ }^{2 *}$ \\ ${ }^{1-2}$ Associate Professor, ${ }^{1-2}$ Dept. of Forensic Medicine, M.P Shah Medical College Jamnagar, PDU Government Medical College Rajkot, \\ Gujarat, India
}

*Corresponding Author: Hetalkumar Kyada

Email: hardiksweet@yahoo.com

\begin{abstract}
Poisoning is the commonest method adopted in India to commit suicide. Pesticide poisoning is an important cause of morbidity and mortality in many countries in the world. Present study was undertaken to evaluate the pattern of poisoning deaths in Rajkot region of Gujarat. Present Retrospective study was conducted from 1st January, 2016 to 31st December, 2018 at department of forensic medicine, PDU govt. medical college, Rajkot. During that period total 8102 autopsies were conducted, out of them 870 cases of fatal poisoning and animal envenomation were selected for study. Average incidence rate of death due to poisoning is around $11 \%$ in Rajkot region. Organophospharus poisoning (36.32\%) was most common followed by Aluminium phosphide poisoning (31.26\%) and these findings were observed in individual age group and in male. Incidence rate is higher in male $(60 \%)$ as compared to female (40\%). Highest numbers of cases were found in age group of 21-30 years (29.43\%). Organophosphorus insecticide was the prime culprit among all poisons. Trends of this region were revealed and result was comparable with previous studies done in same region.
\end{abstract}

Keywords: Poisoning; Organophosphorus fatal, Rajkot, Retrospective.

\section{Introduction}

"All substances are poisons; there is no such thing as a non poison"Paracelsus. The word poison is evolved from the Latin word potion i.e. to drink for health. But in the due course of time, the definition of poison has changed reversibly to its present form i.e. any substance, in any amount, by any route; if it produces harmful effects (3 Ds disease, deleterious effect or death) over the body; it will be labeled as

Poison. ${ }^{1}$

Poisoning is the commonest method adopted in India to commit suicide. ${ }^{2}$ Pesticide poisoning is an important cause of morbidity and mortality in many countries in the world. It has been estimated that $95 \%$ of fatal pesticide poisonings occur in developing countries, many of which are in the Asia Pacific region.

Agriculture based economies, easy availability of pesticides, poverty related socioeconomic problems, lack of adequate protective clothing, and limited treatment facilities are some of the factors contributing to the high morbidity and mortality. ${ }^{3}$ The incidence of insecticide poisoning has steadily increased in recent past and has reached a level where it can be called a social calamity. ${ }^{4}$

This kind of study were done in the year 2007 \& 2012 to 2015 in PDU Govt. medical college \& hospital, Rajkot that shows Organophospharus was the leading substance in all among cases. So in our Study, we tried to find out that any changes occurred or not.

\section{Materials and Methods}

Present Retrospective study was conducted from 1st January, 2016 to 31 st December, 2018 at department of forensic medicine, PDU govt. medical college, Rajkot. During that period 8102 autopsies were conducted, out of them 870 cases (Poisoning cases and animal envenomation cases) were selected for study. This study included all poisoning cases brought to PDU Govt. Medical college \& Hospital for post mortem examination.

Cases were selected from suspected cases of poisoning based on relevant history and postmortem examination, and afterwards confirmed by chemical analysis reports of viscera. Snake bite cases were confirmed by history of relative and postmortem examination.

\section{Results}

Out of total 8102 autopsies, 870 cases (10.74\%) of death due to poisoning were selected for the present study. Average incidence rate of death due to poisoning is around $11 \%$ in Rajkot region (Table 1).

It is evident from Table 2 that death due to Organophospharus poisoning $(36.32 \%)$ was most common followed by Aluminium phosphide poisoning (31.26\%) and these findings were observed in individual age group (Table 4 ) and in male (Table 5). In Female, death due to aluminium phosphide poisoning was most common followed by Organophospharus poisoning (Table 5). In all 3 year, incidence rate of poisoning was almost same.

It is evident from Table 3 that highest numbers of cases were found in age group of 21-30 years (29.43\%), followed by age group of $31-40$ years. (21.49\%).Incidence rate is higher in male $(60 \%)$ as compared to female $(40 \%)$. Highest numbers of male cases were found in age group of 31-40 years $(26.44 \%)$ and female of cases were found in age group of 21-30 years (35.34\%).

Highest no. of OC, ALP, H2SO4, Snake bite and HCL poisoning cases were observed in age group of 21-30 years. Highest no of OP poisoning cases were observed in age group of 31-40 years while highest no. of $\mathrm{CO}$ poisoning cases were observed in age group of 51-60 years (Table 4). Out of all poisoning cases, $87.55 \%$ cases were suicidal and rest $12.45 \%$ cases were accidental. Accidental poisoning 
cases include all $\mathrm{CO}$ poisoning, all snake bite poisoning, 12 OP poisoning and 6 Corrosive poisoning (HCL \& H2SO4). Most common route of administration for poisoning cases was ingestion $(88.36 \%$ ) followed by injection (7.24\%) (All Snake Bite Cases) and inhalation (4.48\%) (All CO poisoning and 12 OP poisoning).

Table 1: Year wise distribution of poison cases

\begin{tabular}{|c|c|c|}
\hline Year & Total Cases & Poison cases \\
\hline 2016 & 2508 & $255(10.02 \%)$ \\
\hline 2017 & 2543 & $296(11.64 \%)$ \\
\hline 2018 & 3051 & $319(10.46 \%)$ \\
\hline Total & 8102 & $870(10.74 \%)$ \\
\hline
\end{tabular}

Table 3: Age group and sex wise distribution of poison cases

\begin{tabular}{|c|c|c|c|}
\hline Age Group & Male & Female & Total \\
\hline$<=10$ & $14(2.68 \%)$ & $9(2.59 \%)$ & $23(2.64 \%)$ \\
\hline $11-20$ & $97(18.58 \%)$ & $57(16.38 \%)$ & $154(17.70 \%)$ \\
\hline $21-30$ & $133(25.48 \%)$ & $123(35.34 \%)$ & $256(29.43 \%)$ \\
\hline $31-40$ & $138(26.44 \%)$ & $49(14.08 \%)$ & $187(21.49 \%)$ \\
\hline $41-50$ & $64(12.26 \%)$ & $50(14.37 \%)$ & $114(13.10 \%)$ \\
\hline $51-60$ & $50(9.58 \%)$ & $41(11.78 \%)$ & $91(10.46 \%)$ \\
\hline $61-70$ & $20(3.83 \%)$ & $15(4.31 \%)$ & $35(4.02 \%)$ \\
\hline$>=70$ & $6(1.15 \%)$ & $4(1.15 \%)$ & $10(1.15 \%)$ \\
\hline & $522(60 \%)$ & $348(40 \%)$ & 870 \\
\hline
\end{tabular}

Table 2: Year and Type of poison wise distribution of poison cases

\begin{tabular}{|l|c|c|c|c|}
\hline Type of poison & $\mathbf{2 0 1 6}$ & $\mathbf{2 0 1 7}$ & $\mathbf{2 0 1 8}$ & Total \\
\hline OP & $93(36.47 \%)$ & $105(35.47 \%)$ & $118(36.99 \%)$ & $316(36.32 \%)$ \\
\hline OC & $35(13.73 \%)$ & $42(14.19 \%)$ & $35(10.97 \%)$ & $112(12.87 \%)$ \\
\hline ALP & $77(30.2 \%)$ & $95(32.09 \%)$ & $100(31.35 \%)$ & $272(31.26 \%)$ \\
\hline H2SO4 & $7(2.75 \%)$ & $8(2.7 \%)$ & $13(4.08 \%)$ & $28(3.22 \%)$ \\
\hline HCL & $13(5.10 \%)$ & $16(5.41 \%)$ & $23(7.21 \%)$ & $52(5.98 \%)$ \\
\hline CO & $10(3.92 \%)$ & $7(2.36 \%)$ & $10(3.13 \%)$ & $27(3.10 \%)$ \\
\hline SB & $20(7.84 \%)$ & $23(7.77 \%)$ & $20(6.27 \%)$ & $63(7.24 \%)$ \\
\hline Total & 255 & 296 & 319 & 870 \\
\hline
\end{tabular}

Table 4: Age group and type of poison wise distribution of poisoning cases

\begin{tabular}{|c|c|c|c|c|c|c|c|c|}
\hline Age Group & OP & OC & ALP & H2SO4 & HCL & CO & SB & Total \\
\hline$<=10$ & $9(2.85 \%)$ & $11(9.82 \%)$ & 0 & 0 & 0 & 0 & $3(4.76 \%)$ & $23(2.64 \%)$ \\
\hline $11-20$ & $79(25 \%)$ & $22(19.64 \%)$ & $41(15.07 \%)$ & 0 & $9(17.31 \%)$ & 0 & $3(4.76 \%)$ & $154(17.70 \%)$ \\
\hline $21-30$ & $59(18.67 \%)$ & $41(36.61 \%)$ & $98(36.03 \%)$ & $14(50 \%)$ & $20(38.46 \%)$ & $8(29.63 \%)$ & $16(25.4 \%)$ & $256(29.43 \%)$ \\
\hline $31-40$ & $82(25.95 \%)$ & $16(14.29 \%)$ & $62(22.79 \%)$ & $7(25 \%)$ & $3(5.77 \%)$ & $7(25.93 \%)$ & $10(15.87 \%)$ & $187(21.49 \%)$ \\
\hline $41-50$ & $56(17.72 \%)$ & $5(4.46 \%)$ & $28(10.29 \%)$ & 0 & $18(34.62 \%)$ & 0 & $7(11.11 \%)$ & $114(13.10 \%)$ \\
\hline $51-60$ & $27(8.54 \%)$ & $11(9.82 \%)$ & $29(10.66 \%)$ & 0 & 0 & $12(44.44 \%)$ & $12(19.05 \%)$ & $91(10.46 \%)$ \\
\hline $61-70$ & 0 & $6(5.36 \%)$ & $12(4.41 \%)$ & $7(25 \%)$ & 0 & 0 & $10(15.87 \%)$ & $35(4.02 \%)$ \\
\hline$>=70$ & $4(1.27 \%)$ & 0 & $2(0.74 \%)$ & 0 & $2(3.85 \%)$ & 0 & $2(3.17 \%)$ & $10(1.15 \%)$ \\
\hline & 316 & 112 & 272 & 28 & 52 & 27 & 63 & 870 \\
\hline
\end{tabular}

Table 5: Sex and type of poison wise distribution of poisoning cases

\begin{tabular}{|l|c|c|c|}
\hline Type of Poison & Male & Female & Total \\
\hline OP & $216(41.38 \%)$ & $100(28.74 \%)$ & $316(36.32 \%)$ \\
\hline OC & $64(12.26 \%)$ & $48(13.79 \%)$ & $112(12.87 \%)$ \\
\hline ALP & $168(32.18 \%)$ & $104(29.89 \%)$ & $272(31.26 \%)$ \\
\hline H2SO4 & $14(2.68 \%)$ & $14(4.02 \%)$ & $28(3.22 \%)$ \\
\hline HCL & $15(2.87 \%)$ & $37(10.63 \%)$ & $52(5.98 \%)$ \\
\hline CO & $24(4.6 \%)$ & $3(0.86 \%)$ & $27(3.10 \%)$ \\
\hline SB & $21(4.02 \%)$ & $42(12.07 \%)$ & $63(7.24 \%)$ \\
\hline Total & $522(60 \%)$ & $348(40 \%)$ & 870 \\
\hline
\end{tabular}




\section{Discussion}

The incidence of poisoning of fatal poisoning in present study was $10.74 \%$, which is comparable with other studies. 5-11 In present study, death due to Organophospharus poisoning (36.32\%) was most common followed by Aluminium phosphide poisoning which is same as previous studies. ${ }^{5,6,11}$ It occur due to easy availability of agriculture poison in market. According to the manner of death, majority of death were suicidal $(87.55 \%)$ followed by accidental (12.45\%). ${ }^{5,9,10,11}$

In the present study, poisoning death cases were higher as $(60 \%)$ in males than females deaths $(40 \%)$ which is comparable with previous studies. ${ }^{5,7-10,11}$ Though all studies were conducted in different parts of India, male predominance was a common and constant feature. In present study, highest numbers of cases were found in age group of 21-30 years (29.43\%), which was also observed in previous studies. ${ }^{5-11}$ Incidence rate were higher in married person $(56.97 \%)$ as compared to unmarried person $(32.34 \%)$ and separated/widow (10.69\%) which was also observed in other studies. ${ }^{5,8,10,11}$ It occur because of stress of the modern life style, failure or less percentage in the exams, scolding from parents or teachers, failure in love, family problems etc.

Death due to poisoning were more observed in lower socioeconomic class $(68.2 \%) .{ }^{6,9,10,11}$ In the present study, the incidence of poisoning was higher in agriculture labourer. ${ }^{8,10,11}$ Majority of Indian population is living in rural area and are farmer by occupation. Farmer are mainly depend upon monsoon for growing crops and failure of monsoon leads to failure to grow crops and less income leads to financial crisis which leads to suicide of farmer.

\section{Conclusion}

This is concluded from above study that death due to fatal poisoning responsible for $10.74 \%$ cases among total autopsy conducted. Deaths due to OP poisoning (36.32\% cases) were most commonly encountered among all fatal poisoning. Males (60\% cases) were more affected as compared to female. 21-30 years $(29.43 \%)$ was most affected age group. Among all fatal poisoning case $87.55 \%$ cases were suicidal. Most common route of administration for poison was ingestion (88.36\% cases). Farmer and workers $(37.48 \%$ cases) were commonly affected. Trends of this region were revealed and result was comparable with previous studies done.

\footnotetext{
Abbreviations

$\mathrm{OP}=$ Organophospharus

$\mathrm{OC}=$ Organochlorine

ALP $=$ Aluminium Phosphide

$\mathrm{H} 2 \mathrm{SO} 4=$ Hydrosulphuric Acid

$\mathrm{HCL}=$ Hydrochloric Acid

$\mathrm{SB}=$ Snake Bite

$\mathrm{CO}=$ Carbon Monoxide
}

Source of Funding: None.

\section{Conflict of Interest: None.}

\section{Reference}

1. Kumar A, Vij K. Trends of poisoning in Chandigarh-A six year autopsy study. J Forensic Med Toxicol. 2001; 18(1): 8-10.

2. Aggarwal P, Handa R, Wali JP. Common poisonings in India. JFMT. 1998;15(1):73-4.

3. Fernando R. Pesticide poisoning in the AsiaPacific region and the role of the regional information network. Clin toxicol. 1995;33(6):677-82.

4. Nigam M, Jain AK, Dubey BP, Sharma VK. Trends of organophosphorus poisoning in Bhopal region An autopsy based study. JIAFM. 2004;26(2):62-5.

5. S. Chaudhary, Prospective study of fatal poisoning cases in Rajkot Region.

6. AK Kapoor. An epidemiological study of Aluminium Phosphide poisoning at Allahabad. IIJFMT. 2006;4(1).

7. JS Dalal. Trends - a post mortem study. JIAFM 1998;20(2):27-31.

8. BD Gupta and PC Vaghela. Profile of fatal poisoning in and around Jamnagar. JIAFM 2005;27(3):145-8.

9. Rajani V. Bhagora. Profile Study of Fatal Poisoning Cases Brought for Postmortem Examination at Mortuary of Sir Takhtsinhji General Hospital, Bhavnagar (Gujarat). Int J Res Med 2015;4(3):59-63.

10. Navinkumar M. Varma Study of Profile of Deaths due to Poisoning in Bhavnagar Region. JIAFM 2011;33(4):313-18.

11. K. N. Pipaliya. Profile of Fatal Poisoning Cases in and Around Rajkot Region: A 3 Years Retrospective Study. IJFMP 2016;9(3):101-04.

How to cite this article: Rathod JS, kyada H. Trends of poisoning in rajkot region- a retrospective study. Int $J$ Forensic Med Toxicol Sci 2019; 4(4):102-4. 